\title{
Air Pollution and the Public Perception Level and Self-Protection Demand in Three Cities of China: Fractional Grey Modelling Analysis
}

\author{
Leping Tu $(\mathbb{D}$ and Yonggang Zhao \\ School of Management Engineering and Business, Hebei University of Engineering, Handan 056038, China \\ Correspondence should be addressed to Yonggang Zhao; 12075255@qq.com
}

Received 21 April 2021; Accepted 6 July 2021; Published 13 July 2021

Academic Editor: Firdous A. Shah

Copyright (c) 2021 Leping Tu and Yonggang Zhao. This is an open access article distributed under the Creative Commons Attribution License, which permits unrestricted use, distribution, and reproduction in any medium, provided the original work is properly cited.

\begin{abstract}
To improve air pollution and human health, a novel grey prediction model with fractional-order accumulation and new information priority accumulation is proposed to analyze and predict the public perception level, self-protection demands, and environmental protection behavior of air pollution. The study in three cities of China shows that the public' perception level will rise rapidly, and the speed will continue to accelerate with the further deterioration of air quality. Among them, Beijing's public perception is the most sensitive and strong. The protection needs of the Tianjin public are the most sensitive. The Shijiazhuang public shows a strong desire for environmental protection. This study will help in understanding the relationship between the public and air quality.
\end{abstract}

\section{Introduction}

Air is a necessary condition for human survival and is closely related to human health [1]. In recent years, air pollution has become serious, because of the increase in industrial production and energy consumption $[2,3]$. Due to the hazards of air pollution to human health, air quality has attracted widespread attention [4]. In fact, the public's attention to air quality is closely related to air quality. First, the public's perception contributes to the promulgation of environmental laws and regulations [5]. Second, public attention to air quality can improve air quality [6]. Finally, the public's response to air treatment measures may determine the efficiency of air treatment measures [7]. Therefore, it is extremely important to understand the public's perception and response to air pollution to improve air quality.

Traditionally, the methods of analyzing the relationship between air quality and public perception and behavior are usually questionnaires and interviews [8]. The collection methods of data not only consume a lot of time, but also may not achieve the expected results [9]. With the advent of the era of big data, the public's network search behavior is widely used in forecast research [10-12]. In fact, the public's Internet search behavior can also be used to analyze air quality. The changing trends of the public's network search data reflect the development trend of air quality $[4,13]$. Besides, different regions have different search habits of air quality [11].

However, there are few studies in forecasting public perception and behavior about air quality. In fact, it is of great significance for preventing major air pollution hazards. As air pollution control is a long process, this paper conducts forecast research on an annual basis. Because there is less annual data, the grey model can be used to solve this problem. Grey prediction models are widely used, because of their effectiveness in short time series prediction [14-16]. Among them, the grey multivariate model has greatly improved the prediction accuracy due to the introduction of influencing factors. For example, the multivariate grey model with optimized fractional order can be well used for the prediction of electricity consumption [17]. A novel discrete grey multivariable model is used to forecast the 
output value of China's high-tech industries [18]. In the research of $\mathrm{CO}_{2}$ emissions and economic growth, the unequal grey Verhulst model is derived [19]. However, there are some deficiencies of the existing literature. First, the grey model is rarely used to analyze public perception and behavior about air pollution. Second, there is no quantitative analysis of the relationship between public perception and behavior and air pollution. Finally, there is no effective way to predict public perception and behavior about air pollution. In this paper, a novel fractional grey multivariate model is proposed to analyze and forecast public perception and behavior about air pollution.

Compared with the existing research, there are some innovations of this paper. Firstly, a novel grey model is proposed to improve the accuracy of prediction. Secondly, based on the analysis of the relationship between the public and air quality, the future public perception level, selfprotection demand, and environmental protection behavior are predicted. Finally, the study results can provide forwardlooking suggestions for protecting air quality and human health.

The rest of this article is organized as follows. The research area and data sources are described in Section 2. The research methods are introduced in Section 3. We analyze the relationship between air quality and perception level, personal protection demands, and environmental protection behavior of the public and make some relevant predictions in Section 4. The conclusion and implication are drawn in Section 5 .

\section{Research Area and Data Sources}

2.1. Research Area. The Beijing-Tianjin-Hebei region is one of the regions with the most severe air pollution in China. It is shown in Figure 1. First of all, the economic structure of Hebei Province is dominated by secondary industry, and coal combustion produces a lot of air pollutants. Secondly, Hebei Province is located in the Central Plains, where pollutants tend to accumulate in large quantities [20]. The ozone pollution in the Beijing-Tianjin-Hebei region has become more and more serious, which poses a challenge to the pollution mitigation strategy and needs to be further adjusted to solve this problem [21]. Beijing, Tianjin, and Shijiazhuang are the cities with the most serious air pollution in the Beijing-Tianjin-Hebei region, and the air quality of the three cities is closely correlated [22]. Therefore, Beijing, Tianjin, and Shijiazhuang are studied to improve air quality in this paper.

\subsection{Data Sources}

2.2.1. Air Quality Index. The air quality index (AQI) is a dimensionless index that describes the overall status of the city's ambient air quality. The index comprehensively considers the pollution levels of six pollutants $\left(\mathrm{SO}_{2}, \mathrm{NO}_{2}\right.$, $\mathrm{PM}_{10}, \mathrm{PM}_{2.5}, \mathrm{CO}$, and $\mathrm{O}_{3}$ ) in the AQI Technical Regulations (HJ633-2012). The greater the value of the AQI, the greater the degree of comprehensive pollution. Therefore, the AQI can be used to reflect the air quality [23]. To assess the air pollution, AQI from 2014 to 2019 in Beijing, Tianjin, and Shijiazhuang is collected from the China Air Quality Online Monitoring and Analysis Platform (https://www.aqistudy.cn/).

2.2.2. Baidu Index. Baidu index is a data-sharing platform based on Baidu's massive netizens' behavior data and is the weighted sum of the frequency of every keyword in Baidu web search. Data sources include the number of netizens' behaviors such as reading, commenting, forwarding, praising, and disliking. In fact, the Baidu index can be used to explore the relationship between air quality and public behavior [11]. To select representative keywords, keywords need to be filtered, because grey correlation analysis is often used to analyze the degree of correlation between two variables. The higher the degree of grey correlation, the higher the degree of correlation between the two variables [24]. In this paper, based on the grey correlation analysis, the annual Baidu index for keywords with a high grey correlation with the AQI (Figure 2) is obtained from the Baidu index official website (https://index.baidu.com/).

(1) Perception Level. The level of public perception of air pollution reflects people's risk assessment and attitudes towards air pollution [25]. In fact, the level of perception depends not only on the degree of public exposure to air pollution, but also on the perception of air pollution and the sensitivity to air pollution threats [26]. The public perception based on air pollution can not only directly reflect air quality but also indirectly reflect personal protection demands and environmental protection behavior [27]. Based on the grey correlation analysis, the Baidu index $\mathrm{PM}_{2.5}$, smog, and air quality are selected to assess the level of public perception of air pollution in Beijing, Tianjin, and Shijiazhuang.

(2) Personal Protection Demands. According to the protection motivation theory [28], the level of public perception of air pollution determines the personal protection demands of the public. The public's personal protection demands depend on the public's perception level of air pollution. Besides, the need for self-protection is affected by the public's responsiveness, the effectiveness of protective measures, and the cost of practice [29]. Based on the grey correlation analysis, the Baidu index of masks, air purifiers, and $\mathrm{PM}_{2.5}$ detectors is used to evaluate the public's personal protection demands.

(3) Environmental Protection Behavior. Public environmental protection behavior is considered as the public's selfprotection based on long-term consideration [30]. Therefore, the level of public perception of air pollution also affects the public's environmental protection behavior. Not only that, the public's environmental protection behavior can determine whether the environmental protection policies are effectively implemented [31]. The environmental protection behavior of the public includes energy saving and emission reduction, green travel, and environmental protection. Therefore, the Baidu index of energy saving and 


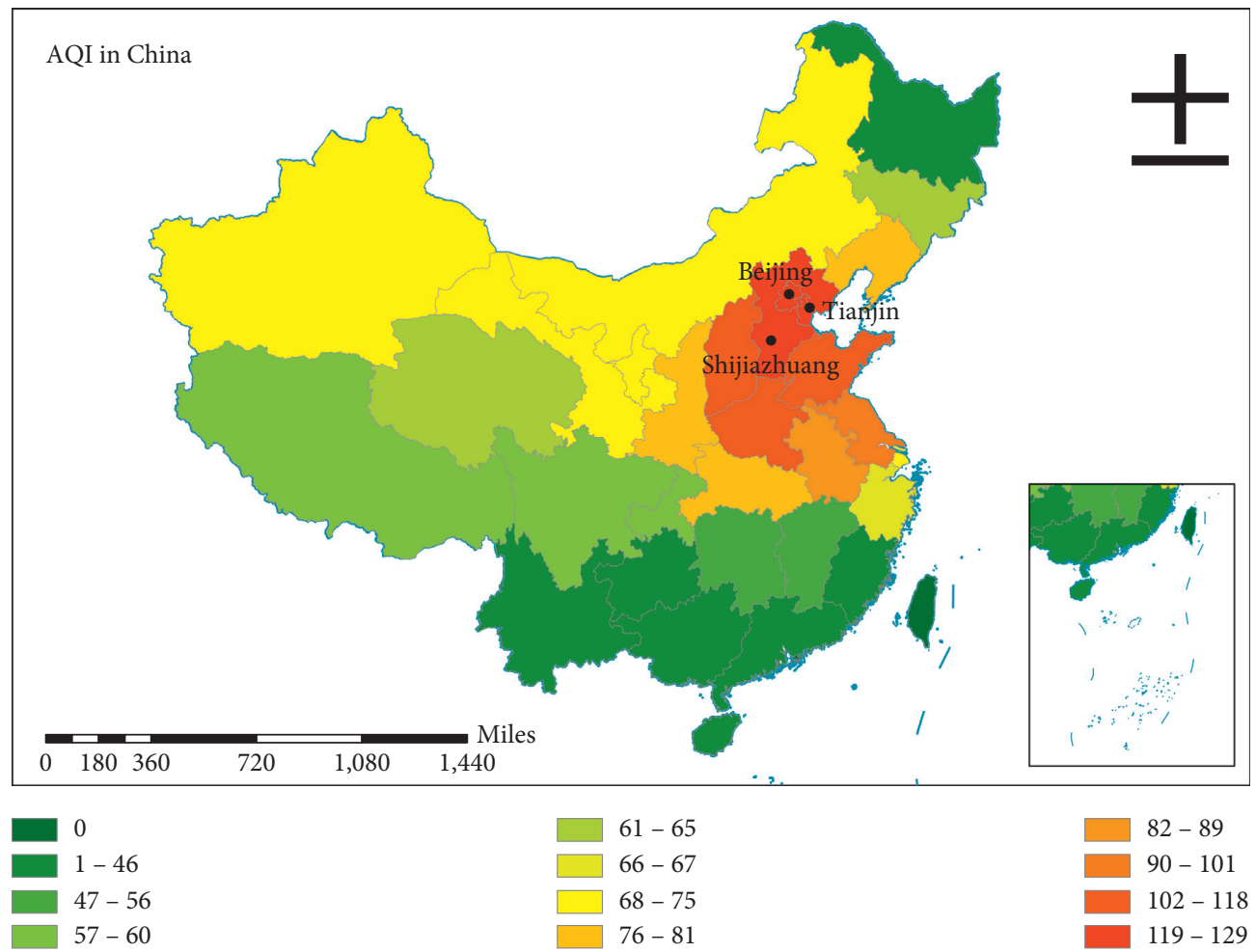

FIgURE 1: Location and AQI spatial patterns of Beijing, Tianjin, and Shijiazhuang in China.

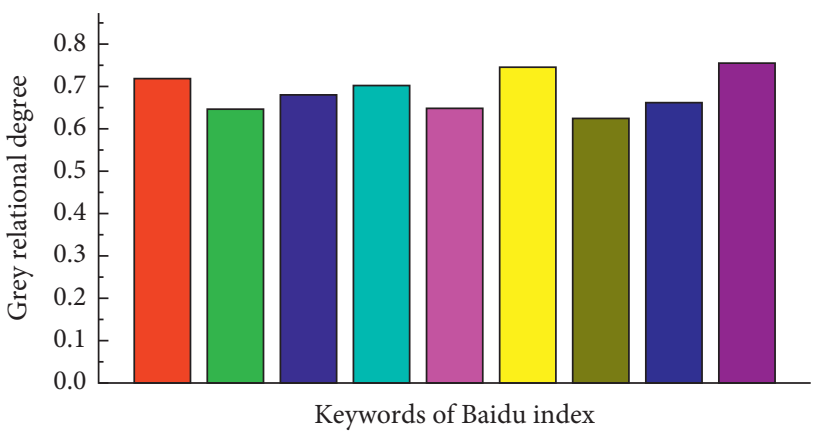

Perception level: $\quad$ Personal protection demands:

$\square$ PM2.5
Smog
Air quality
Environmental protection behavior:
Energy saving and emission reduction
Environmental protection behaviors
Environmental protection

FIgURE 2: Grey correlation degree between AQI and Baidu index.

emission reduction, green travel, and environmental protection are used to reflect public environmental protection behavior.

\section{Research Methods}

The GMC $(1, N)$ model can improve the accuracy of the grey model [32]. Considering the fractional order accumulation method [33] and new information priority accumulation [34], the GMC $(1, N)$ model is optimized by using a combination of fractional-order accumulation and new information priority accumulation (FNGMC $(1, N)$ ). The FNGMC $(1, N)$ model is given as follows:

The original nonnegative sequence is conventionally represented as

$$
X_{l}^{(0,0)}=\left\{x_{l}^{(0,0)}(1), x_{l}^{(0,0)}(2), \ldots, x_{l}^{(0,0)}(n)\right\}, \quad l=1,2, \ldots, m .
$$

Step 1. By using $x_{l}^{(r, 0)}(k)=\sum_{i=1}^{k} C_{k-i+r-1}^{k-i} x_{l}^{(0,0)}(i)$, the $r$-order accumulation sequence is

$$
X_{l}^{(r, 0)}=\left\{x_{l}^{(r, 0)}(1), x_{l}^{(r, 0)}(2), \ldots, x_{l}^{(r, 0)}(n)\right\} .
$$

where $C_{r-1}^{0}=1, C_{k}^{k+1}=0$, and $C_{k-i+r-1}^{k-i}=((k-i+r-1)(k-$ $i+r-2), \ldots,(r+1) r /(k-i) !)$.

By using $x_{l}^{(r, \lambda)}(m)=\sum_{j=1}^{m} \lambda^{m-j} x_{l}^{(r, 0)}(j)$, the $r$-order accumulation sequence of new information priority is

$$
X_{l}^{(r, \lambda)}=\left\{x_{l}^{(r, \lambda)}(1), x_{l}^{(r, \lambda)}(2), \ldots, x_{l}^{(r, \lambda)}(n)\right\} .
$$


Step 2. The whitened equation of $\operatorname{FNGMC}(1, N)$ model is written as

$$
\frac{d x_{1}^{(r, \lambda)}(t)}{d t}+b_{1} x_{1}^{(r, \lambda)}(t)=b_{2} x_{2}^{(r, \lambda)}(t)+b_{3} x_{3}^{(r, \lambda)}(t)+\cdots+b_{N} x_{N}^{(r, \lambda)}(t)+u
$$

where $b_{1}, b_{2}, \ldots, b_{N}$ are driving parameters, and $u$ is the

$$
\left[\widehat{b}_{1}, \widehat{b}_{2}, \ldots, \widehat{b}_{N}, \widehat{u}\right]^{T}=\left(B^{T} B\right)^{-1} B^{T} Y
$$
control parameter. Among them, the greater the driving parameters, the greater the influence of the corresponding factors. The grey derivative is conventionally represented as $\left(d x_{1}^{(r, \lambda)}(t) / d t\right)=x_{1}^{(r, \lambda)}(t+1)-x_{1}^{(r, \lambda)}(t)$. The least-squares solution of the model parameters is

where

$$
\begin{aligned}
& Y=\left[\begin{array}{c}
x_{1}^{(r, \lambda)}(2)-x_{1}^{(r, \lambda)}(1) \\
x_{1}^{(r, \lambda)}(3)-x_{1}^{(r, \lambda)}(2) \\
\vdots \\
x_{1}^{(r, \lambda)}(n)-x_{1}^{(r, \lambda)}(n-1)
\end{array}\right], \\
& B=\left[\begin{array}{ccccc}
-\frac{\left(x_{1}^{(r, \lambda)}(1)+x_{1}^{(r, \lambda)}(2)\right)}{2} & \frac{\left(x_{2}^{(r, \lambda)}(1)+x_{2}^{(r, \lambda)}(2)\right)}{2} & \ldots & \frac{\left(x_{N}^{(r, \lambda)}(1)+x_{N}^{(r, \lambda)}(2)\right)}{2} & 1 \\
-\frac{\left(x_{1}^{(r, \lambda)}(2)+x_{1}^{(r, \lambda)}(3)\right)}{2} & \frac{\left(x_{2}^{(r, \lambda)}(2)+x_{2}^{(r, \lambda)}(3)\right)}{2} & \ldots & \frac{\left(x_{N}^{(r, \lambda)}(2)+x_{N}^{(r, \lambda)}(3)\right)}{2} & 1 \\
\vdots & \vdots & \ddots & \vdots \\
-\frac{\left(x_{1}^{(r, \lambda)}(n-1)+x_{1}^{(r, \lambda)}(n)\right)}{2} \frac{\left(x_{2}^{(r, \lambda)}(n-1)+x_{2}^{(r, \lambda)}(n)\right)}{2} & \ldots \frac{\left(x_{N}^{(r, \lambda)}(n-1)+x_{N}^{(r, \lambda)}(n)\right)}{2} & \vdots
\end{array}\right],
\end{aligned}
$$

Step 3. Then, the approximate time-response function of FNGMC $(1, N)$ model is

$$
\widehat{x}_{1}^{(r, \lambda)}(t)=x_{1}^{(0,0)}(1) e^{-b_{1}(t-1)}+\sum_{\tau=2}^{t}\left\{e^{-b_{1}(t-\tau+0.5)} \frac{f(\tau)+f(\tau-1)}{2}\right\},
$$

Step 4. Then, the sequence by the inverse accumulated generating operator of new information priority is

$$
\widehat{x}_{1}^{(r, 0)}(1)=x_{1}^{(0,0)}(1), \widehat{x}_{1}^{(r, 0)}(k)=\widehat{x}_{1}^{(r, \lambda)}(k)-\lambda \widehat{x}_{1}^{(r, \lambda)}(k-1), \quad k=2,3, \ldots, n
$$

Finally, the predicted value is given by the inverse accumulated generating operator of $r$-order.

$$
\widehat{X}_{1}^{(0,0)}=\left\{\widehat{x}_{1}^{(0,0)}(1), \widehat{x}_{1}^{(0,0)}(2), \ldots, \widehat{x}_{1}^{(0,0)}(n)\right\},
$$

where $\widehat{x}_{1}^{(0,0)}(k)=\widehat{x}_{1}^{(r, 0)(1-r, 0)}(k)-\widehat{x}_{1}^{(r, 0)(1-r, 0)}(k-1)$.
The proposed FNGMC $(1, N)$ model can be transformed into some existing grey models. When $\lambda=1$, the FNGMC ( 1 , $N)$ model yields the FGMC $(1, N)$ model. When $r=1$, the FNGMC $(1, N)$ model yields the $\operatorname{GMCN}(1, N)$ model. When $\lambda=1$ and $r=1$, the FNGMC $(1, N)$ model yields the GMC $(1, N)$ model. As an improved model, the proposed model 
not only can be flexibly transformed into a general model, but also has high prediction accuracy.

The mean absolute percentage error (MAPE) is used to verify the accuracy of the FNGMC $(1, N)$ model. The smaller the MAPE, the higher the prediction accuracy of the model. It is calculated as

$$
\mathrm{MAPE}=\frac{1}{n} \frac{\sum_{t=1}^{n}\left|x_{1}^{(0,0)}(t)-\hat{x}_{1}^{(0,0)}(t)\right|}{x_{1}^{(0,0)}(t)} \times 100 \% .
$$

The following example can demonstrate the validity of the FNGMC $(1, N)$ model. The data comes from literature [35]. The tensile strength of the material is regarded as predicted sequence $\left(X_{1}\right)$, while the Brinell hardness is regarded as influence sequence $\left(X_{2}\right)$. The first five sets of data are used to determine the model, while the last five sets of data are used to test the model. The $\mathrm{GMC}_{T}(1,2), \mathrm{GMC}_{G}$ $(1,2)$, and RDGM $(1,2)$ models are used for comparison. The RMSPEPR and RMSPEPO of the four models are shown in Table 1.

It can be seen from Table 1 that the RMSPEPR and RMSPEPO of the FNGMC $(1, N)$ model are as small as $0.14 \%$ and $1.72 \%$, respectively. It shows that the FNGMC $(1, N)$ model is better than other competition models.

\section{Empirical Study}

4.1. Analysis and Prediction for Perception Levels of Air Pollution in Beijing, Tianjin, and Shijiazhuang. As shown in Figure 3, the AQI of Beijing, Tianjin, and Shijiazhuang decreases from 2014 to 2018 . It indicates that the air quality of the three cities has been improved. Besides, the Baidu index of $\mathrm{PM}_{2.5}, \mathrm{smog}$, and air quality shows a downward trend. Specifically, Beijing's AQI declined year by year, and the search index declined steadily. The AQI of Tianjin and Shijiazhuang increased from 2015 to 2017, and the search index also started to rise. This shows that the change of AQI has a significant impact on the public's perception for air quality. Moreover, this influence is positive; that is to say, the decline of AQI and the public perception level also decline. However, from 2018 to 2019, with the increase of AQI in the three cities, the Baidu index still kept declining. Presumably, there may be two reasons for this phenomenon. First, the influence of air quality on public perception level changes. Second, in recent years, the improvement of air quality has reduced the public's perception sensitivity, which has delayed this influence. Therefore, it is necessary to predict the perception level in the future. By the $\operatorname{FNGMC}(1,2)$ model, the fitting results of the Baidu index in three cities are obtained (Table 2).

From Table 2, the MAPE in the three cities is low. This shows that the FNGMC $(1,2)$ model has high accuracy. According to the model results, the AQI has a positive impact on perception level. It is consistent with the previous analysis. Therefore, the FNGMC $(1,2)$ model can be used to predict the perception level from 2020 to 2024. Based on the changes from 2018 to 2019, the estimated AQI from 2020 to 2024 is obtained at growth rates of $0.95,0.97,1.03,1.05$, and
1.1. Then, the estimated AQI of Beijing, Tianjin, and Shijiazhuang from 2020 to 2024 is shown in Table 3.

By substituting the AQI of three cities from 2020 to 2024 into the corresponding FNGMC $(1, N)$ models, the prediction results of $\mathrm{PM}_{2.5}$, smog, and air quality from 2020 to 2024 can be obtained. As shown in Figure 4, the search index of $\mathrm{PM}_{2.5}$ increased with the growth rate of AQI increase from 2020 to 2024 . This shows that the reduction of air quality improves the public's perception of air pollution. In fact, $\mathrm{PM}_{2.5}$ is the main cause of smog formation. Compared with smog and air quality, the search for $\mathrm{PM}_{2.5}$ reflects a deeper perception. Besides, the public's deep perception of Beijing is stronger in terms of the range of change.

Similar to the prediction results of $\mathrm{PM}_{2.5}$, a larger AQI leads to a higher smog perception level (Figure 5). However, compared with the search index of $\mathrm{PM}_{2.5}$, the search index of smog is lower, which shows that the public's perception of smog weather not only stays on the surface, but also penetrates its causes. Besides, from the comparison results of cities, Beijing's search index is larger, indicating that Beijing's public perception of smog is still higher than that of Tianjin and Shijiazhuang. Judging from the change range, the Beijing public has higher perception sensitivity.

Similar to $\mathrm{PM}_{2.5}$ and smog, larger AQI leads to a higher air quality search index (Figure 6). Baidu index of air quality reflects the basic public perception of air quality. Compared with $\mathrm{PM}_{2.5}$ and smog, this perception is more comprehensive, and it includes other air pollution situations besides smog. By comparison, it is found that the public in Beijing still maintains a high level of perception of other air pollution. Besides, from the change range, this comprehensive perception is the most sensitive. Considering that the average AQI in Beijing in 2019 is as low as 86, it is speculated that the public perception level may promote air control.

To sum up, the reduction of air quality promotes the improvement of perception level at all levels, including indepth causes $\left(\mathrm{PM}_{2.5}\right)$, major air pollution $(\mathrm{smog})$, and comprehensive perception (air quality). From the prediction curves of the three indexes, the change curve of the search index caused by AQI change is a concave curve, which shows that higher AQI causes more sensitive perception. On the contrary, lower AQI leads to less sensitive perception. Retrospectively, this can explain the abnormal phenomenon from 2018 to 2019, which may be the perception delay caused by the decrease of public sensitivity to air pollution.

\subsection{Analysis and Prediction for Personal Protection Demands} of Air Pollution in Beijing, Tianjin, and Shijiazhuang. The Baidu index of masks, air purifiers, and $\mathrm{PM}_{2.5}$ detectors reflects the public's personal protection needs. Taking Beijing as an example, from 2014 to 2019, with the decrease of air quality index, masks and air purifiers in Beijing showed a downward trend (Figure 7). Baidu index of Beijing masks decreased from 245 times/day to 155 times/day, Baidu index of air purifiers decreased from 680 times/day to 257 times/ day, and the Baidu index of $\mathrm{PM}_{2.5}$ detectors changed little (from 82 times/day to 76 times). The changes in Tianjin and Shijiazhuang are similar to those in Beijing. It can be seen 
TABLE 1: The RMSPEPR and RMSPEPO of four models.

\begin{tabular}{lcccc}
\hline & $\mathrm{GMC}_{T}(1,2)$ & $\mathrm{GMC}_{G}(1,2)$ & RDGM $(1,2)$ & FNGMC $(1,2)$ \\
\hline RMSPEPR (\%) & 0.41 & 0.25 & 0.1 & 0.09 \\
RMSPEPO (\%) & 2.92 & 2.84 & 2.86 & 1.72 \\
\hline
\end{tabular}

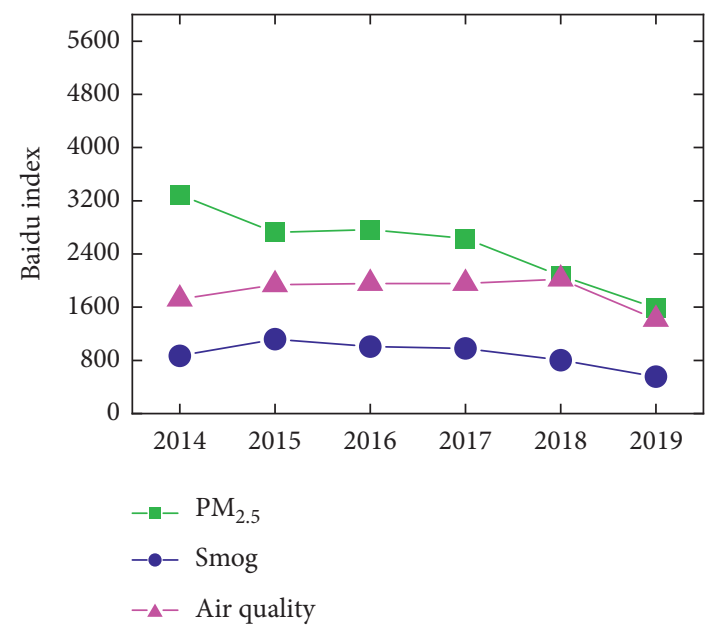

(a)

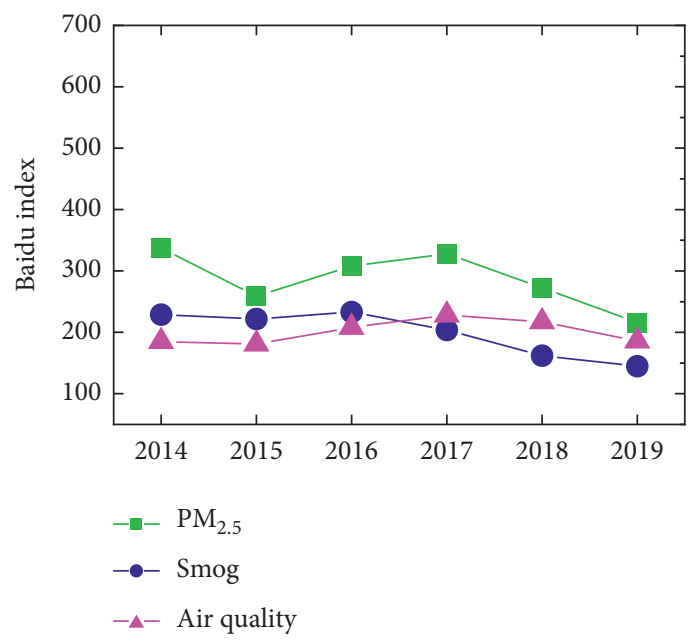

(c)

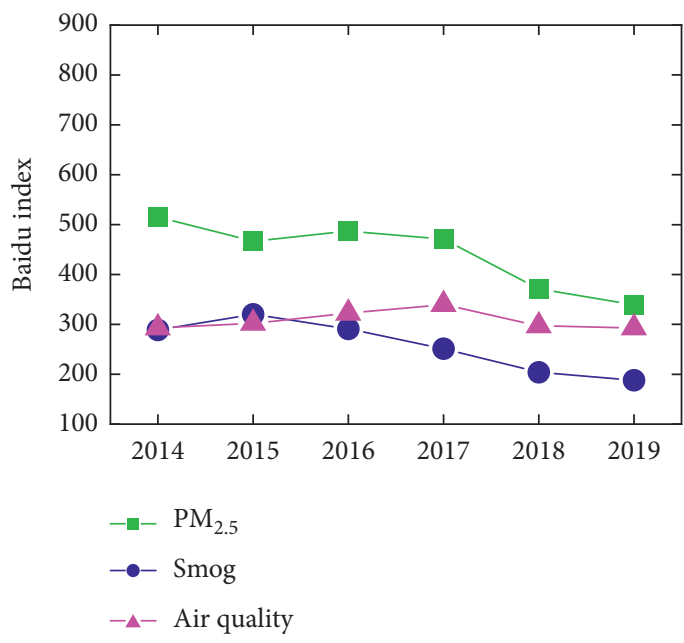

(b)

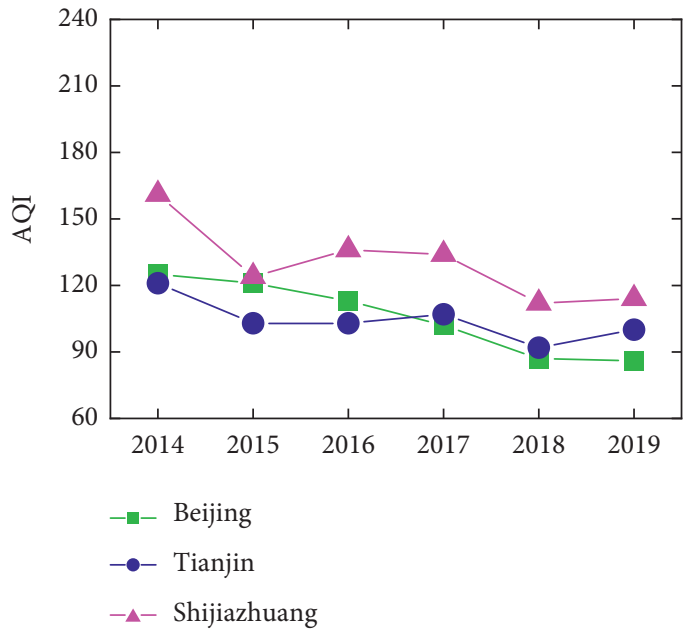

(d)

FIgure 3: The relationship between Baidu index of the perception levels and AQI. (a) Beijing. (b) Tianjin. (c) Shijiazhuang. (d) AQI of three cities.

TABLE 2: The results of the Baidu index by the FNGMC $(1,2)$ model in three cities.

\begin{tabular}{lcccccccc}
\hline & Baidu index & 2014 & 2015 & 2016 & 2017 & 2018 & 2019 & MAPE (\%) \\
\hline \multirow{3}{*}{ Beijing } & $\mathrm{PM}_{2.5}$ & 3286 & 2749 & 2838 & 2603 & 2130 & 1626 & 1.61 \\
& Smog & 868 & 1046 & 1053 & 945 & 746 & 565 & 3.93 \\
& Air quality & 1721 & 1738 & 1948 & 2071 & 1865 & 1423 & 4.18 \\
\hline \multirow{3}{*}{ Tianjin } & $\mathrm{PM}_{2.5}$ & 515 & 467 & 490 & 451 & 392 & 335 & 1.91 \\
& Smog & 289 & 320 & 291 & 239 & 206 & 185 & 1.22 \\
& Air quality & 293 & 302 & 322 & 327 & 310 & 288 & 1.64 \\
\multirow{3}{*}{ Shijiazhuang } & $\mathrm{PM}_{2.5}$ & 337 & 259 & 308 & 323 & 281 & 222 & 1.20 \\
& Smog & 229 & 222 & 210 & 204 & 174 & 138 & 3.69 \\
& Air quality & 185 & 189 & 210 & 228 & 217 & 187 & 1.03 \\
\hline
\end{tabular}


TABLE 3: The estimated AQI from 2020 to 2024 in three cities.

\begin{tabular}{|c|c|c|c|c|c|c|}
\hline & Growth rate & 2020 & 2021 & 2022 & 2023 & 2024 \\
\hline \multirow{5}{*}{ Beijing } & 0.95 & 82 & 78 & 74 & 70 & 67 \\
\hline & 0.97 & 83 & 81 & 78 & 76 & 74 \\
\hline & 1.03 & 89 & 91 & 94 & 97 & 100 \\
\hline & 1.05 & 90 & 95 & 100 & 105 & 110 \\
\hline & 1.1 & 95 & 104 & 114 & 126 & 139 \\
\hline \multirow{5}{*}{ Tianjin } & 0.95 & 95 & 90 & 86 & 81 & 77 \\
\hline & 0.97 & 97 & 94 & 91 & 89 & 86 \\
\hline & 1.03 & 103 & 106 & 109 & 113 & 116 \\
\hline & 1.05 & 105 & 110 & 116 & 122 & 128 \\
\hline & 1.1 & 110 & 121 & 133 & 146 & 161 \\
\hline \multirow{5}{*}{ Shijiazhuang } & 0.95 & 108 & 103 & 98 & 93 & 88 \\
\hline & 0.97 & 111 & 107 & 104 & 101 & 98 \\
\hline & 1.03 & 117 & 121 & 125 & 128 & 132 \\
\hline & 1.05 & 120 & 126 & 132 & 139 & 145 \\
\hline & 1.1 & 125 & 138 & 152 & 167 & 184 \\
\hline
\end{tabular}

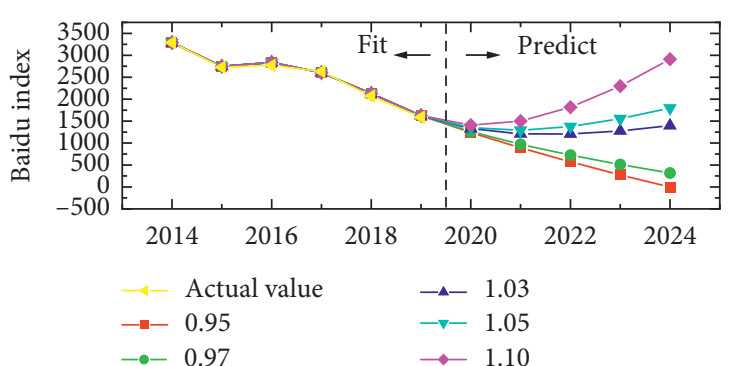

(a)

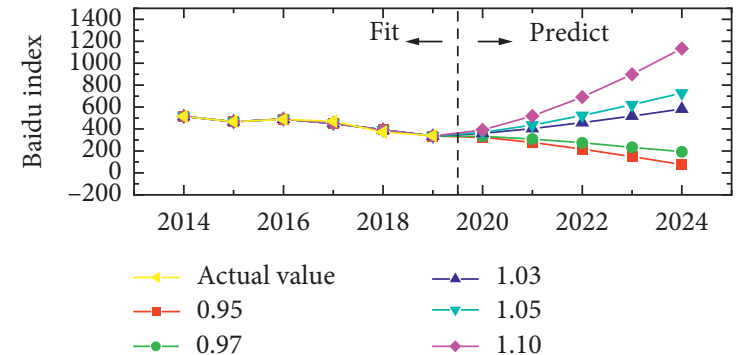

(b)

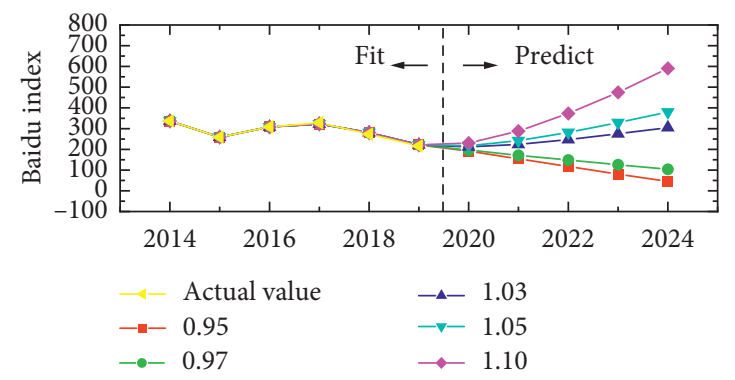

(c)

Figure 4: The predicted Baidu index of $\mathrm{PM}_{2.5}$ in Beijing (a), Tianjin (b), and Shijiazhuang (c).

that, with the improvement of air quality, the public's demand for masks and air purifiers has decreased, while the demand for $\mathrm{PM}_{2.5}$ detectors has not changed much. The public's demand for personal protection has generally declined. However, the air quality began to deteriorate from 2018 to 2019, and the public's demand for personal protection is still declining, which may pose a potential threat.

Therefore, the FNGMC $(1,2)$ model is used to forecast the personal protection needs of the public in Beijing, Tianjin, and Shijiazhuang. The results are shown in Figure 8. With the growth rate of AQI increasing, the Baidu index of masks in Tianjin also increased from 2020 to 2024 . However, Beijing and Shijiazhuang continue to decline in 2020 and do not start to rise until 2021. In terms of the range of change, the public demand for the mask in Tianjin is the strongest.
Compared with the mask, the use of air purifier is a more effective way to reduce the harm of air pollution. Similar to the predicted results of masks, the larger AQI leads to higher demand for air purifiers (Figure 9). However, the search index of air purifiers is higher than that of masks. This shows that, with the aggravation of air pollution, the public tends to take more effective protective measures. In three cities, Tianjin's search index is larger. This indicates that Tianjin's public demand for air pollution protection is higher than that of Beijing and Shijiazhuang. For the change range, Tianjin public has higher demand sensitivity.

Unlike masks and air purifiers, $\mathrm{PM}_{2.5}$ detector has no substantial protective effect, but it can serve as a reminder and warning. According to the search index, larger AQI still causes higher demand for $\mathrm{PM}_{2.5}$ detector (Figure 10). 


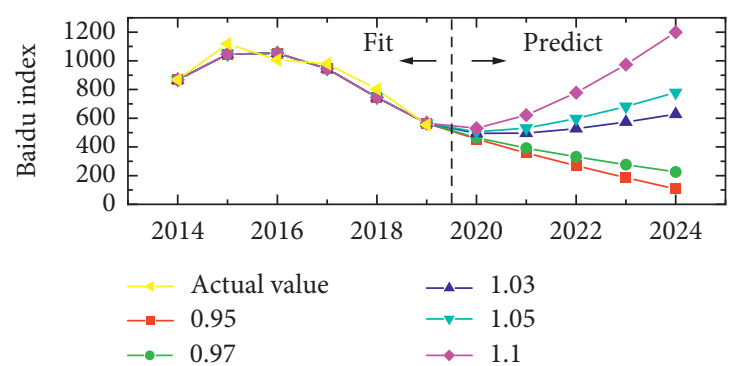

(a)

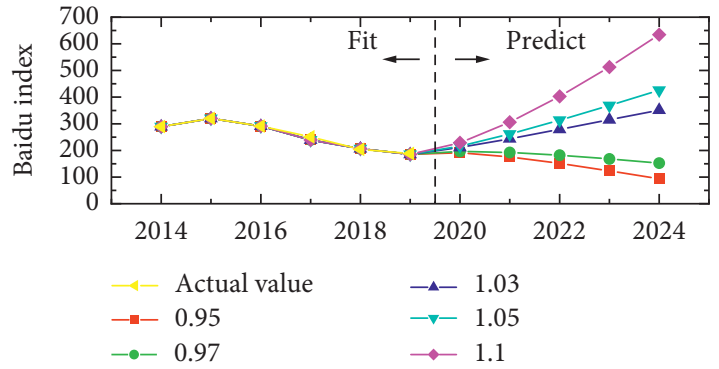

(b)

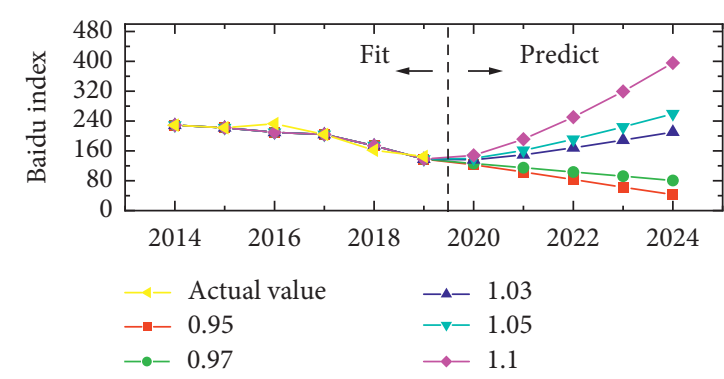

(c)

Figure 5: The predicted Baidu index of smog in Beijing (a), Tianjin (b), and Shijiazhuang (c).

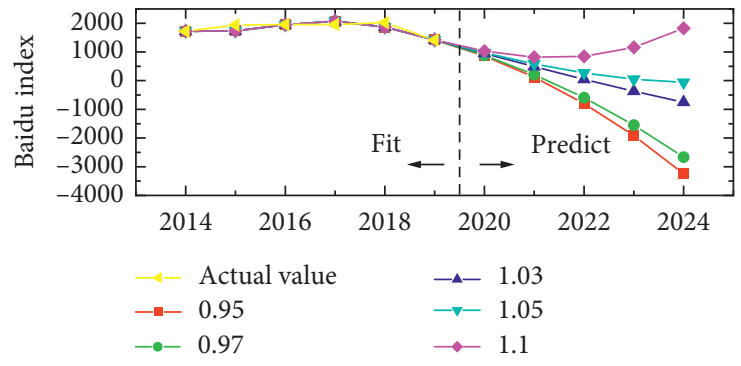

(a)

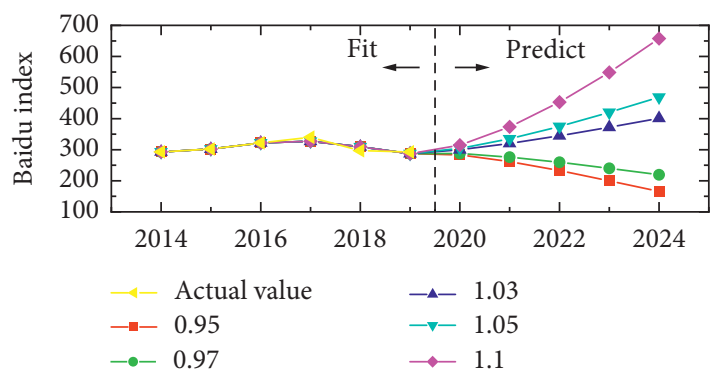

(b)

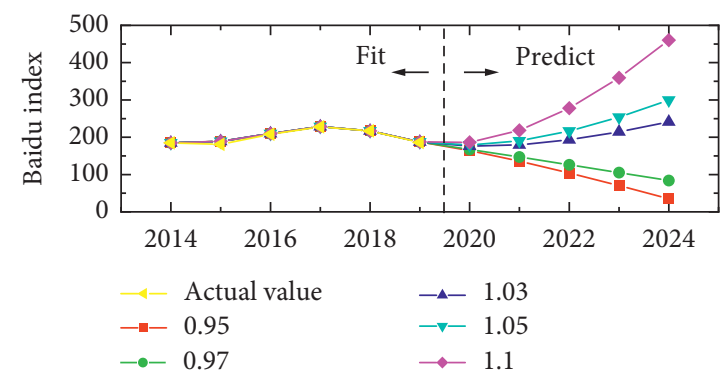

(c)

FIgure 6: The predicted Baidu index of air quality in Beijing (a), Tianjin (b), and Shijiazhuang (c). 


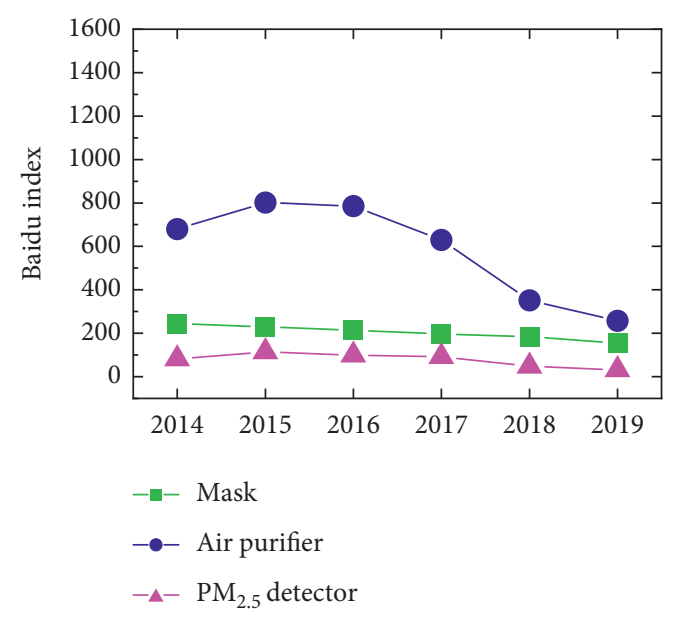

(a)

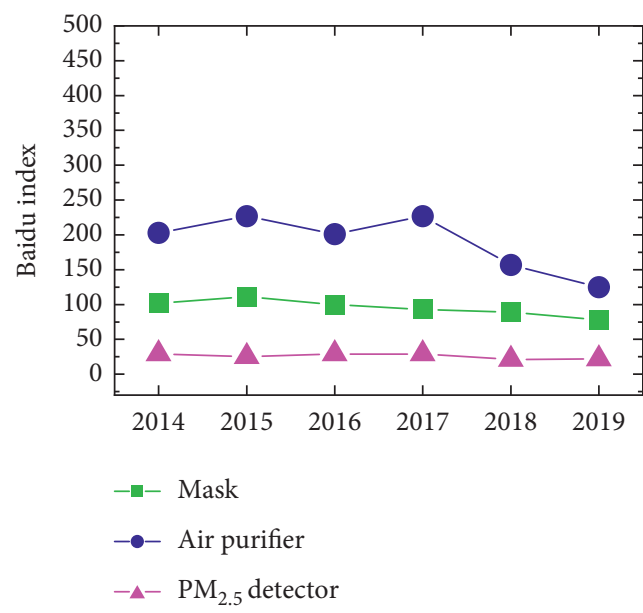

(c)

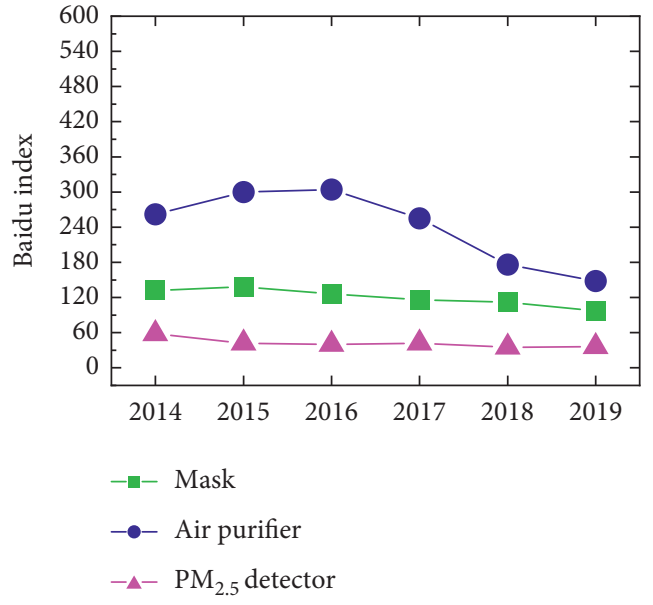

(b)

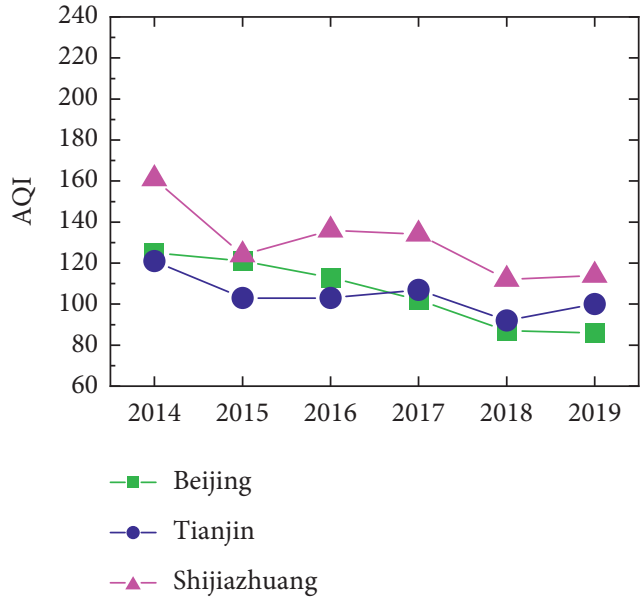

(d)

FIgURE 7: The relationship between Baidu index of the personal protection demands and AQI. (a) Beijing. (b) Tianjin. (c) Shijiazhuang. (d) AQI of three cities.

However, compared with masks and air purifiers, the demand for $\mathrm{PM}_{2.5}$ detectors is the lowest, which indicates that the public is more inclined to take substantial protective measures. Besides, it is found that the public demand for $\mathrm{PM}_{2.5}$ detector in Beijing is higher than that in Tianjin and Shijiazhuang. From the change range, Beijing public is most sensitive to the demand of $\mathrm{PM}_{2.5}$ detector.

\subsection{Analysis and Prediction for Environmental Protection} Behavior of Air Pollution in Beijing, Tianjin, and Shijiazhuang. The public's search index on energy conservation and emission reduction, green travel, and environmental protection reflects the public's environmental protection behavior. Taking Beijing as an example, from 2014 to 2019, with the decline of air quality index, the Baidu index of energy conservation and emission reduction shows a downward trend (from 164 to 127), while the Baidu index of green travel and environmental protection shows an upward trend (green tourism from 121 to 138, environmental protection from 152 to 199) (Figure 11). The changes in Tianjin and Shijiazhuang are similar to those in Beijing. As a matter of fact, environmental protection often appears in the form of slogans, which cannot indicate concrete measures. Green travel and energy saving and emission reduction reflect the actual actions of the public, among which energy saving and emission reduction are more effective in air control. This shows that when the air quality is improved, the public tends to be inefficient and easy to implement. However, the air quality began to deteriorate from 2018 to 2019, and the changing trend of public environmental protection behavior remained unchanged, which may lead to further deterioration of air quality.

Therefore, the FNGMC $(1,2)$ model is used to predict the public's environmental protection behavior in Beijing, Tianjin, and Shijiazhuang. The results are shown in 


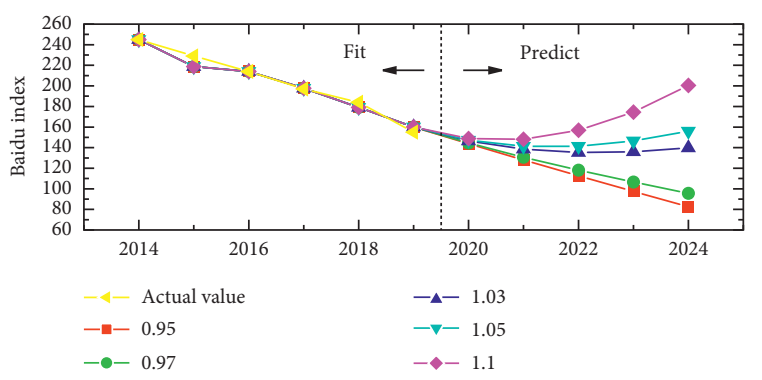

(a)

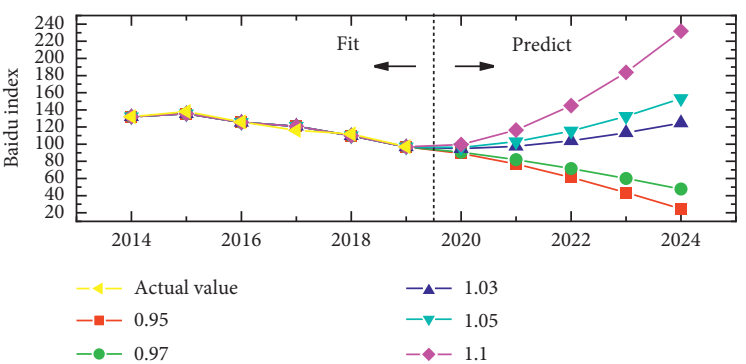

(b)

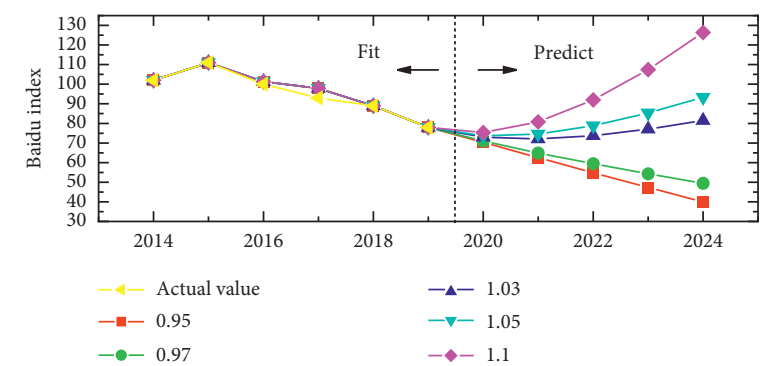

(c)

Figure 8: The predicted Baidu index of mask in Beijing (a), Tianjin (b), and Shijiazhuang (c).

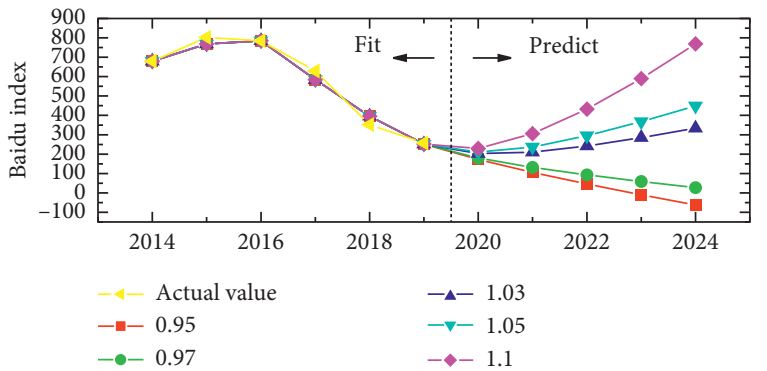

(a)

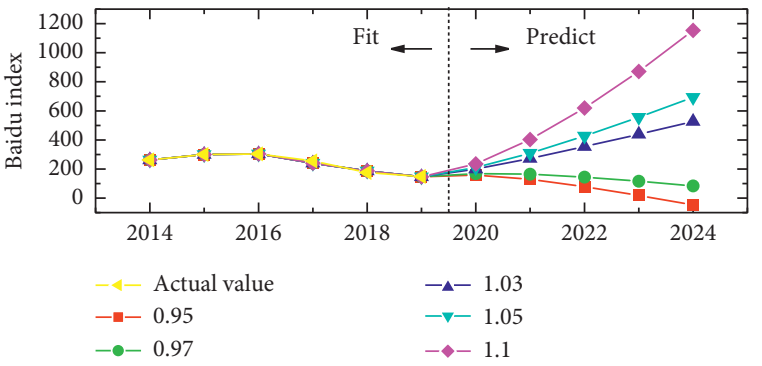

(b)

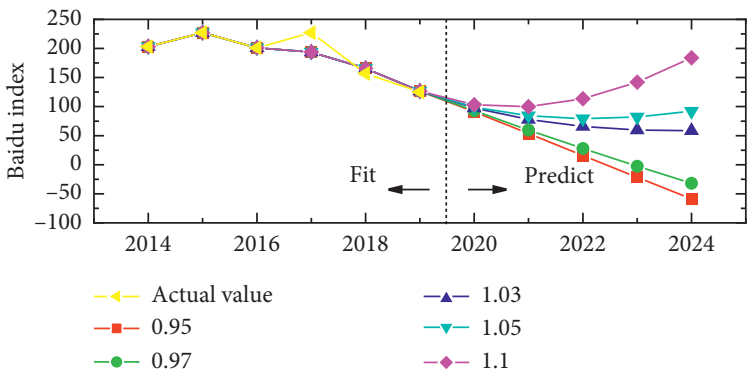

(c)

Figure 9: The predicted Baidu index of air purifier in Beijing (a), Tianjin (b), and Shijiazhuang (c).

Figure 12. With the increasing growth rate of AQI, the Baidu index of energy conservation and emission reduction in Tianjin begins to pick up in 2020. On the contrary, Beijing and Shijiazhuang continued to decline in 2020 and began to pick up in 2021. Among them, Shijiazhuang's Baidu index on energy conservation and emission reduction is picking up faster than Beijing. This may be due to the more severe air pollution in Shijiazhuang.

Compared with energy saving and emission reduction, the efficiency for air protection of green travel is low. From 


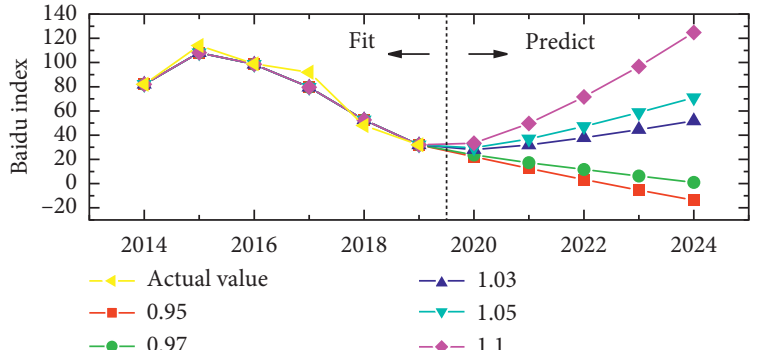

(a)

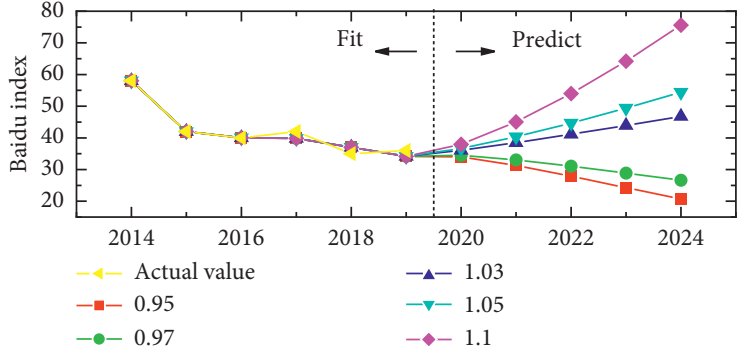

(b)

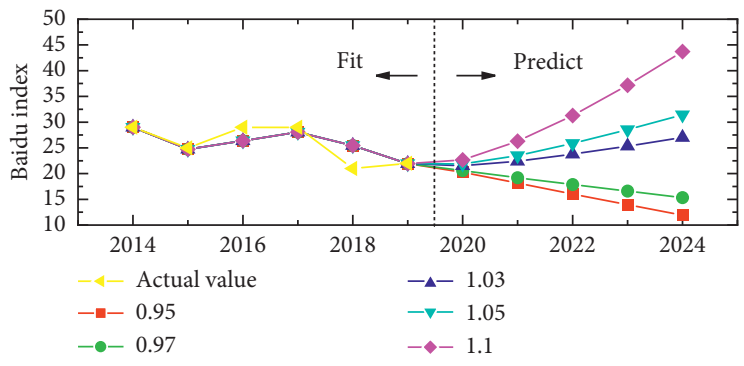

(c)

Figure 10: The predicted Baidu index of PM2.5 detector in Beijing (a), Tianjin (b), and Shijiazhuang (c).

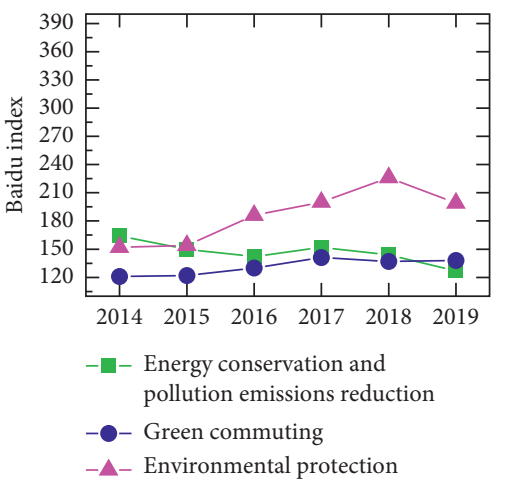

(a)

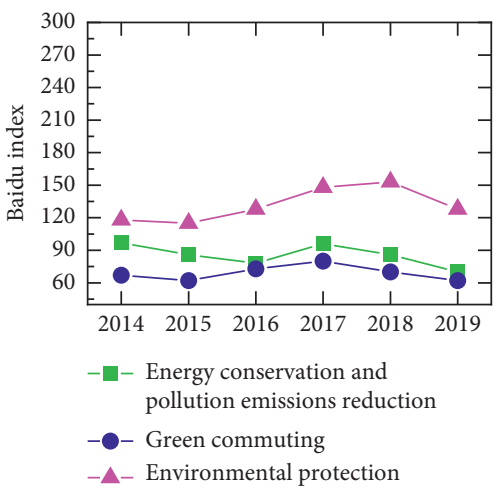

(b)

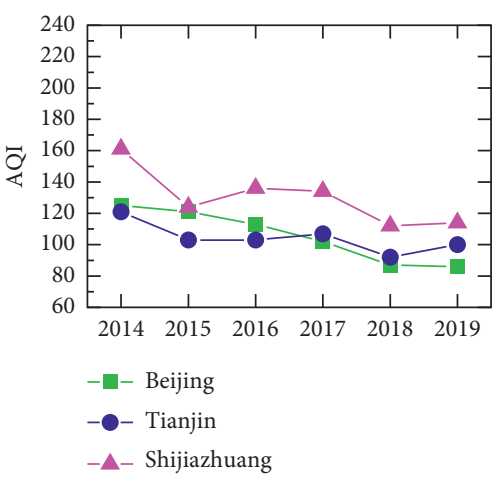

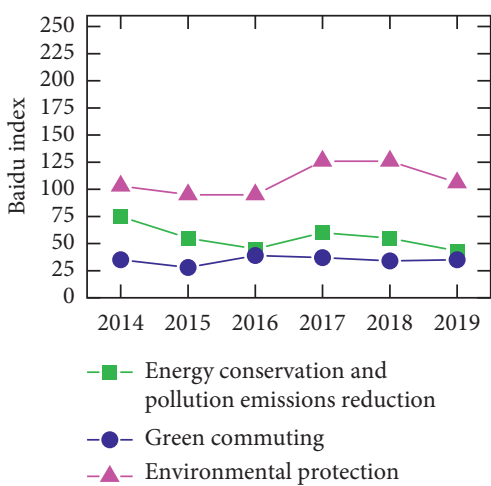

(c)

(d)

Figure 11: The relationship between Baidu index of environmental protection behavior and AQI. (a) Beijing. (b) Tianjin. (c) Shijiazhuang. (d) AQI of three cities. 


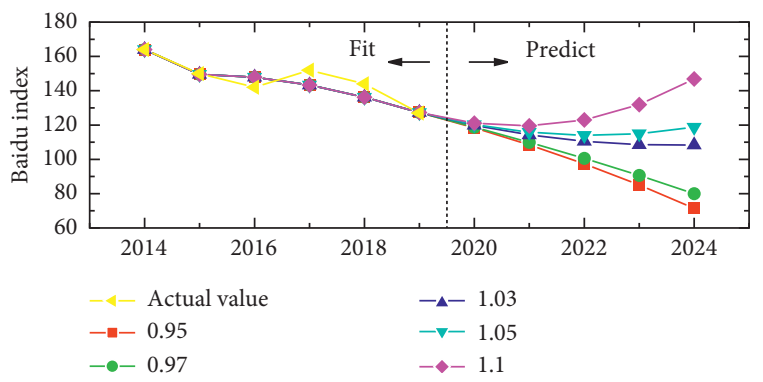

(a)

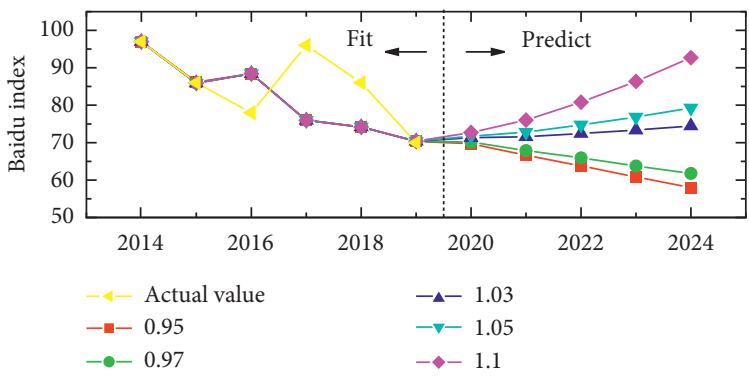

(b)

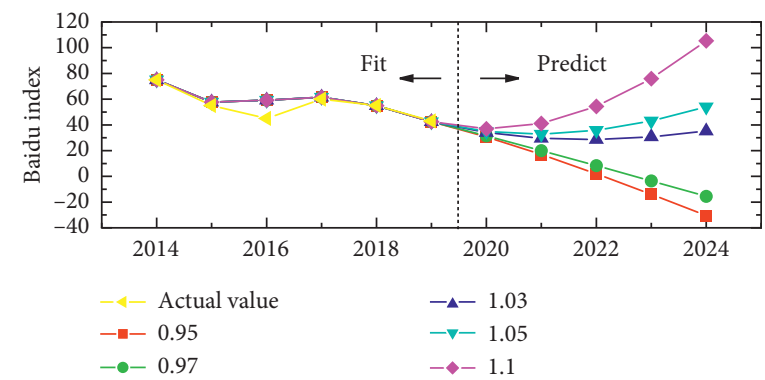

(c)

Figure 12: The predicted Baidu index of energy conservation and pollution emissions reduction in Beijing (a), Tianjin (b), and Shijiazhuang (c).

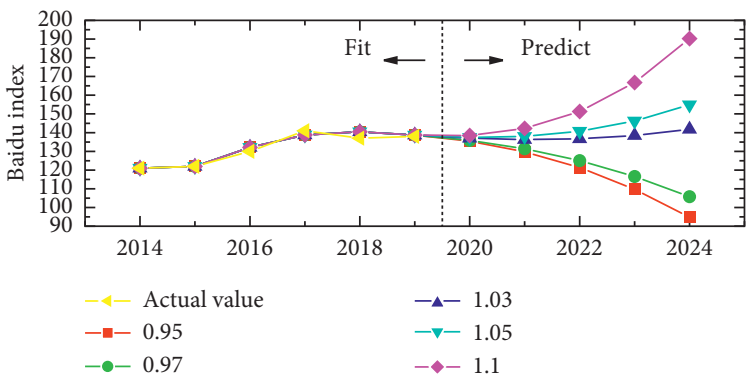

(a)

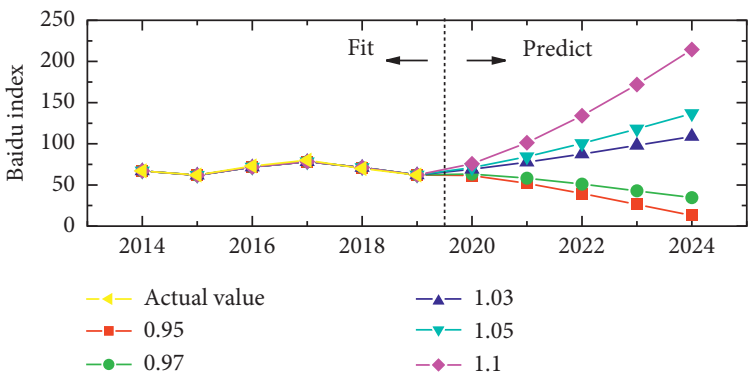

(b)

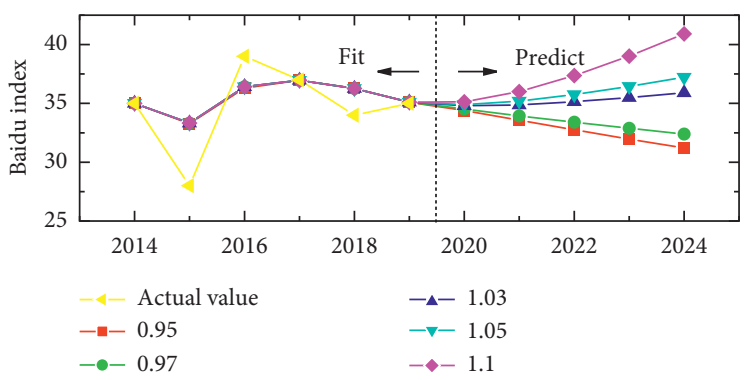

(c)

Figure 13: The predicted Baidu index of Green commuting in Beijing (a), Tianjin (b), and Shijiazhuang (c).

Figure 13, the larger AQI leads to the higher Baidu index of green travel. This shows that the aggravation of air pollution stimulates more green travel behavior. Besides, Beijing's search index is bigger than Tianjin and Shijiazhuang. It shows that Beijing's public awareness of environmental protection is stronger. Judging from the change range, Beijing's forecast curve is concave to a greater extent. It shows that, with the continuous deterioration of air quality, the public practice of green travel in Beijing is more intense.

Different from energy saving and emission reduction and green travel, environmental protection belongs to conceptual air quality control. The search may be just for understanding, without an in-depth understanding of specific protective behavior, so protective measures may 


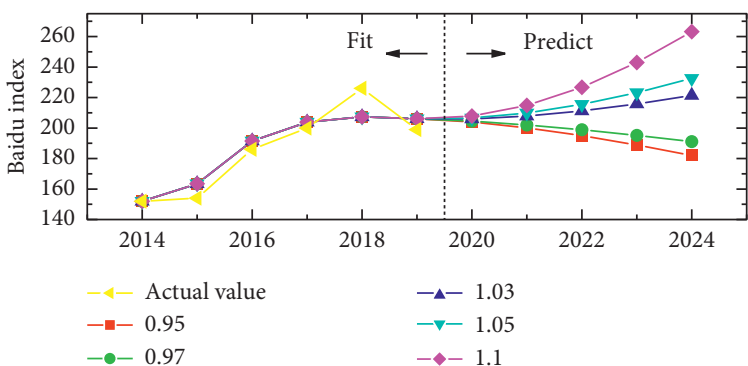

(a)

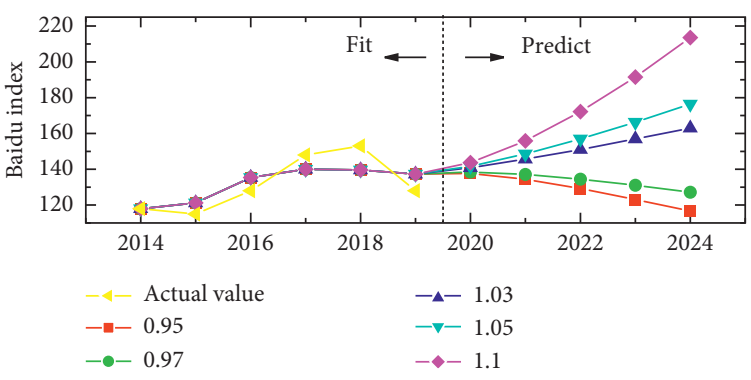

(b)

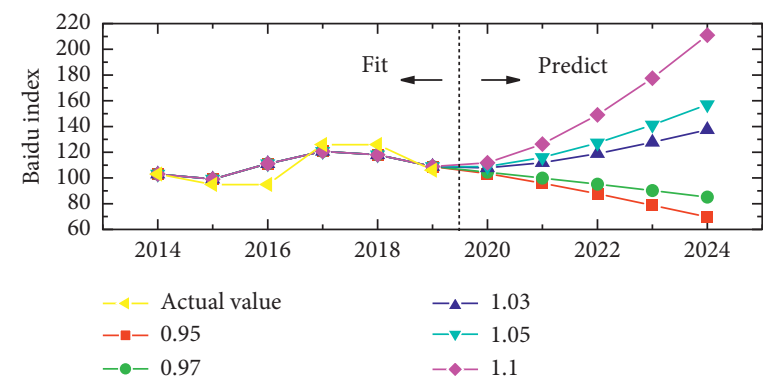

(c)

Figure 14: The predicted Baidu index of environmental protection in Beijing (a), Tianjin (b), and Shijiazhuang (c).

not be taken. According to the prediction results, a larger AQI still leads to a higher Baidu index of environmental protection (Figure 14). However, compared with energy conservation and emission reduction and green travel, the Baidu index of environmental protection is the highest, which shows that most of the public do not know enough about air protection measures and can further tap the public's environmental protection power in the future. Besides, it is found that the public's Baidu index of environmental protection in Beijing is higher than that in Tianjin and Shijiazhuang. This shows that Beijing has the greatest potential environmental protection force from the public, and the future environmental protection can be started from the public perspective.

\section{Conclusion and Implication}

In this paper, the public's perception level and self-protection demand of air pollution in Beijing, Tianjin, and Shijiazhuang are analyzed to improve air pollution. First of all, the Baidu index is used to measure the public's perception level and self-protection demand of air pollution. Then, an improved FNGMC $(1, N)$ model is proposed. The numerical results show that the model has good prediction performance. According to the analysis and forecast results of the public's perception level and self-protection demand of air pollution, the main conclusions are as follows. Firstly, the public's perception of air pollution in three cities has been declining from 2014 to 2019. However, this perception level will rise in the future due to the deterioration of air quality. Among them, Beijing has the highest public perception level. Secondly, the public's self-protection demand for air pollution in three cities has been declining from 2014 to 2019.
However, the self-protection demand will rise in the future due to the deterioration of air quality. Among them, Tianjin has the highest self-protection demand.

For the suggestions, first of all, environmental protection departments should raise public awareness of air pollution and make air control a positive demand, rather than a mandatory response. Secondly, it is necessary to assess the needs of people exposed to air pollution and formulate targeted air pollution protection programs. Finally, refer to the degree of air pollution and the public's willingness to formulate appropriate prevention and control measures.

For the limitations and future research directions, the Baidu index is often difficult to cover the people with the most serious air pollution, such as the elderly, children, and outdoor workers. In addition, there are few keywords in Baidu Index studied in this paper, which are not enough to express the real situation. Generally speaking, it is feasible to use the improved FNGMC $(1, N)$ model and Baidu index to predict the public's perception level and self-protection demand of air pollution. Future research will be promoted nationwide, and the keyword types of the Baidu index will be further improved. Besides, the exposed groups of air pollution will be further divided to obtain more accurate research results.

\section{Data Availability}

The data used to support the findings of this study are included within the article.

\section{Conflicts of Interest}

The authors declare that they have no conflicts of interest. 


\section{Acknowledgments}

This work was supported by the Social Science Federation Project of Handan (2021058 and 2021077).

\section{References}

[1] A. A. Almetwally, M. Bin-Jumah, and A. A. Allam, "Ambient air pollution and its influence on human health and welfare: an overview," Environmental Science and Pollution Research, vol. 27, no. 20, pp. 24815-24830, 2020.

[2] Y. Wang, T. Lu, and Y. Qiao, "The effect of air pollution on corporate social responsibility performance in high energyconsumption industry: evidence from Chinese listed companies," Journal of Cleaner Production, vol. 280, Article ID 124345, 2021.

[3] Y. Zheng, J. Peng, J. Xiao et al., "Industrial structure transformation and provincial heterogeneity characteristics evolution of air pollution: evidence of a threshold effect from China," Atmospheric Pollution Research, vol. 11, no. 3, pp. 598-609, 2020.

[4] S. Zhong, Z. Yu, and W. Zhu, "Study of the effects of air pollutants on human health based on Baidu indices of disease symptoms and air quality monitoring data in beijing, China," International Journal of Environmental Research and Public Health, vol. 16, no. 6, 1014 pages, 2019.

[5] J. Chen, J. Huang, X. Huang et al., "How does new environmental law affect public environmental protection activities in China? Evidence from structural equation model analysis on legal cognition," Science of The Total Environment, vol. 714, Article ID 136558, 2020.

[6] K. Yang, Y. Shi, Y. Luo et al., "Assessing spatiotemporal air environment degradation and improvement represented by $\mathrm{PM}_{2.5}$ in China using two-phase hybrid model," Sustainable Cities and Society, vol. 59, Article ID 102180, 2020.

[7] W. Qu, G. Qu, X. Zhang et al., "The impact of public participation in environmental behavior on haze pollution and public health in China," Economic Modelling, vol. 98, pp. 319-335, 2021.

[8] T. Reames and M. Bravo, "People, place and pollution: investigating relationships between air quality perceptions, health concerns, exposure, and individual- and area-level characteristics," Environment International, vol. 122, pp. 244-255, 2019.

[9] A. Benedetti, B. Levis, G. Ruecker et al., "An empirical comparison of three methods for multiple cutoff diagnostic test meta-analysis of the Patient Health Questionnaire-9 (PHQ-9) depression screening tool using published data vs. individual level data," Research Synthesis Methods, vol. 11, 2020.

[10] D. Kostopoulos, S. Meyer, and C. Uhr, "Google search volume and individual investor trading," Journal of Financial Markets, vol. 49, Article ID 100544, 2020.

[11] W. Li, G. Yang, and X. Li, "Correlation between $\mathrm{PM}_{2.5}$ pollution and its public concern in China: evidence from Baidu index," Journal of Cleaner Production, vol. 293, Article ID 126091, 2021.

[12] L. Wang, X. Zhou, M. Lu et al., "Impacts of haze weather on tourist arrivals and destination preference: analysis based on Baidu Index of 73 scenic spots in Beijing, China," Journal of Cleaner Production, vol. 273, Article ID 122887, 2020.

[13] D. Dong, X. Xu, W. Xu et al., "The relationship between the actual level of air pollution and residents' concern about air pollution: evidence from shanghai, China," International
Journal of Environmental Research and Public Health, vol. 16, no. 23, 4784 pages, 2019.

[14] Y. Cao, K. Yin, X. Li et al., "Forecasting $\mathrm{CO}_{2}$ emissions from Chinese marine fleets using multivariable trend interaction grey model," Applied Soft Computing, vol. 104, Article ID 107220, 2021.

[15] H. Duan and X. Pang, "A multivariate grey prediction model based on energy logistic equation and its application in energy prediction in China," Energy, vol. 229, Article ID 120716, 2021.

[16] M. Kiran, P. Shanmugam, A. Mishra et al., "A multivariate discrete grey model for estimating the waste from mobile phones, televisions, and personal computers in India," Journal of Cleaner Production, vol. 293, Article ID 126185, 2021.

[17] L. Wu, X. Gao, Y. Xiao et al., "Using a novel multi-variable grey model to forecast the electricity consumption of Shandong Province in China," Energy, vol. 157, pp. 327-335, 2018.

[18] S. Ding, "A novel discrete grey multivariable model and its application in forecasting the output value of China's hightech industries," Computers \& Industrial Engineering, vol. 127, pp. 749-760, 2019.

[19] Z. Wang and Q. Li, "Modelling the nonlinear relationship between $\mathrm{CO}_{2}$ emissions and economic growth using a PSO algorithm-based grey Verhulst model," Journal of Cleaner Production, vol. 207, pp. 214-224, 2019.

[20] L. Jiang, S. He, and H. Zhou, "Spatio-temporal characteristics and convergence trends of $\mathrm{PM}_{2.5}$ pollution: a case study of cities of air pollution transmission channel in Beijing-TianjinHebei region, China," Journal of Cleaner Production, vol. 256, Article ID 120631, 2020.

[21] X. Qiu, Q. Ying, S. Wang et al., "Significant impact of heterogeneous reactions of reactive chlorine species on summertime atmospheric ozone and free-radical formation in north China," Science of the Total Environment, vol. 693, Article ID 133580, 2019.

[22] N. Bei, X. Li, and X. Tie, "Impact of synoptic patterns and meteorological elements on the wintertime haze in the Beijing-Tianjin-Hebei region, China from 2013 to 2017," Science of the Total Environment, vol. 704, Article ID 135210, 2020.

[23] B. Fu, X. Gao, and L. Wu, "Grey relational analysis for the AQI of Beijing, Tianjin, and Shijiazhuang and related countermeasures," Grey Systems-Theory and Application, vol. 8, no. 2, pp. 156-166, 2018.

[24] F. Yuan and C. Lee, "Intelligent sales volume forecasting using Google search engine data," Soft Computing, vol. 24, no. 3, pp. 2033-2047, 2020.

[25] S. Pu, Z. Shao, M. Fang et al., "Spatial distribution of the public's risk perception for air pollution: a nationwide study in China," Science of The Total Environment, vol. 655, pp. 454-462, 2019.

[26] D. Wu, "Empirical study of knowledge withholding in cyberspace: integrating protection motivation theory and theory of reasoned behavior," Computers in Human Behavior, vol. 105, Article ID 106229, 2020.

[27] G. Bradley, Z. Babutsidze, A. Chai et al., "The role of climate change risk perception, response efficacy, and psychological adaptation in pro-environmental behavior: a two nation study," Journal of Environmental Psychology, vol. 68, Article ID 101410, 2020.

[28] M. Clarke, Z. Ma, S. Snyder et al., "Understanding invasive plant management on family forestlands: an application of protection motivation theory," Journal of Environmental Management, vol. 286, Article ID 112161, 2021. 
[29] S. Verkoeyen and S. Nepal, "Understanding scuba divers' response to coral bleaching: an application of protection motivation theory," Journal of Environmental Management, vol. 231, pp. 869-877, 2019.

[30] J. Soares, I. Miguel, C. Venâncio et al., "Public views on plastic pollution: knowledge, perceived impacts, and pro-environmental behaviours," Journal of Hazardous Materials, vol. 412, Article ID 125227, 2021.

[31] Y. Tan and X. Mao, "Assessment of the policy effectiveness of central inspections of environmental protection on improving air quality in China," Journal of Cleaner Production, vol. 288, Article ID 125100, 2021.

[32] T. Tien, "A research on the grey prediction model GM $(1, \mathrm{n})$," Applied Mathematics and Computation, vol. 218, no. 9, pp. 4903-4916, 2012.

[33] L. Wu, S. Liu, L. Yao et al., "Grey system model with the fractional order accumulation," Communications in Nonlinear Science and Numerical Simulation, vol. 18, no. 7, pp. 1775-1785, 2013.

[34] L. Wu and Z. Zhang, "Grey multivariable convolution model with new information priority accumulation," Applied Mathematical Modelling, vol. 62, pp. 595-604, 2018.

[35] X. Ma and Z. Liu, "Research on the novel recursive discrete multivariate grey prediction model and its applications," Applied Mathematical Modelling, vol. 40, no. 7-8, pp. 4876-4890, 2016. 